\title{
Pedagogical Risks as Consequences of the Coronavirus COVID-19 Spread
}

\author{
Gromova N.S.*
}

\author{
Ural state University of Economics, Yekaterinburg, Russia \\ *Corresponding author. Email: n.s.gromova@usue.ru
}

\begin{abstract}
This article examines the specifics of the educational process transformation in the context of the pandemic, analyzes formal and substantive changes in educational activities. The innovations significance in the educational process that have entered the educational space as a consequence of the coronavirus COVID-19 spread and possible risks are determined. Special attention is paid to pedagogical risks, the results of which are of the delayed character, so may appear not in the process of teaching students, but in the professional activities of specialists in a few years. Three groups of risks are forecast. The main reason of these risks is insufficient universal competencies formation that ensure the social skills development in the learning process. Such pedagogical risks can provoke various consequences (social, professional and personal). The first group of risks is associated with a students' socialization process violation in a predominantly remote format of interaction between participants in educational relations. The second group of risks is the professional one. It is associated with the predominance of the training theoretical component over the practical one. The third group is the personal risks that are associated with the formation of an subject individual behavior strategy. All risks are considered as hypothetical. The possibility of their leveling is noted, taking into account the educational strategy adjustment.
\end{abstract}

Keywords: pedagogical risk, universal competencies, educational system, coronavirus, pandemic

\section{INTRODUCTION}

In the context of the coronavirus pandemic spread, the world community has been functioning for more than six months. The first forecasts have either proved to be true, or have demonstrated their persistent failure. It is time to summarize the results of the transformations that have affected various aspects of human life. The changes that were initially considered sporadic and had an impact on certain areas of social and public life have become systemic over time, and the solution of emerging problems has become complex. So, gradually, all spheres of human life were transformed into a new reality due to the spread of the coronavirus COVID-19.

The greatest interest in the scientific community is caused by changes that have occurred in the field of economics and law. Inasmuch, the result of changes is clearly expressed, and the consequences are easily calculated and verified. The economic processes reverse and the new legal norms production have new legal norms have provided the states viability and minimized social problems, but created conditions for hybrid threats of delayed nature.

The relevance of this research is determined by the need to study deep changes in those industries where risks of identifying problems may appear due to abrupt transformations at later stages of social development. This applies to those social spheres, where the human factor is important. One of these areas is education, because the formation of personality is a long and complex process, and all the factors that were involved in this process can affect the result in different ways.

The educational system has undergone a significant transformation during the pandemic. It had an impact not only on the form of educational organizations work, but also on the educational process content. The educational process at all education levels has changed. This includes the ammount of hours, forms of work, ways of interaction between participants in educational relations. This led to the development of new methods or adaptation of the old ones, the new educational materials creation and the interactive technical tools in the work inclusion.

At the same time, education involves not only learning and teaching activities, but also pedagogical activites, as well as activities for the development of the individual, which remains out of the field of view of most scientists. Article 2 of the Federal law "On Education in the Russian Federation" contains a key definition. The education is interpreted through the lexemes "fostering" and "teaching". These content elements become particularly relevant with the introduction of new higher education Federal Educational Standard, which include a number of universal competencies that reflect the indicators of students' personal growth, i.e. aimed at the formation of so-called "soft skills". Therefore, issues related to the risks 
of the pandemic impact on the fostering process has to be studied.

This work is characterized by novelty, since it contributes to the formation of experience in understanding the pedagogical consequences of the coronavirus spread. In this paper, we define and characterize not formal, but substantive changes on how the pandemic affected the educational process side. It is important to note that in contrast to the formal side, where it is possible to determine the immediate qualitative and quantitative indicators of changes, the content of the educational process is measured only in the long term, when today's students start their professional activities. Therefore, we can calculate the number of training hours that were lost due to the switch to a new working format. But we cannot calculate the impact of this switch on the training level and the future specialist's quality of education. The most important thing, in our opinion, is the pedagogical contingent-risks associated with students' characteristics. The aim of the study is to determine the coronavirus spread pedagogical consequences, i.e. to identify the existing risks in the formation of future specialists' universal competencies in higher education institutions, taking into account the learning process transformation.

\section{RESEARCH METHODS}

The research material is the existing Federal and regional levels program documents, educational organizations local acts and educational materials, as well as their scientific and methodological understanding, presented in recent research.

The information legal block analysis, based on the theoretical methods used in the research to achieve this goal (deduction and induction methods, as well as generalization method and content analysis), allowed us to form an idea of the problem current state. We have also understood that many local acts adopted during the pandemic, as noted by G. B. Romanovsky, "restrict basic human rights and do not comply with some Federal laws" [1]. We understand that such acts were adopted in an extraordinary situation and the restrictions were forced. But it should be noted that without further legislation systematization in the regulating educational relations field. some violations can become systemic. The Russian Ministry of education and science adopted new higher education Federal Educational Standards in August 2020. These standards are a kind of response to the challenges that have become obvious under the impact of the coronavirus spread in the process of educational transformations. The transformations were launched this spring.

A meaningful analysis of Russian documents clearly indicates that the issues of an educational nature and the formation of a full-fledged personality in the learning process are understood as a priority. Universal competencies that should be formed are, first of all, a set of over-professional skills that affect the professional and personal qualities of a person. Team work and leadership
(УК-3), communication (УК-4), cross-cultural interaction (УK-5), and other competencies included in the Federal Educational Standards require the educational organization to pay attention not only to the formal indicators of learning, but also to the educational process content. According to article 12.1 of the Federal law "on education in the Russian Federation" came into operation on $01 / 09 / 2020$. This law said that the pedagogical working program had to be included into educational programs. This will help to form the student's personality both in terms of developing the qualities necessary for carrying out work at a high professional level, and in terms of developing social skills, necessary for successful socialization of the individual.

The coronavirus spread has significantly changed the educational space. It has created conditions for possible ambiguous consequences of the current period, i.e. it has led to the occurrence of risks for further system development and the its participants characteristics. The risks can be classified as formal and informative, respectively. This research is based on such theoretical methods as analysis, synthesis, classification, analogy, and abstraction in the systematization of existing positions in science process. As a result, we have found that there are more research on formal risks.

The subject of most of the research devoted to the education problems during the pandemic is the introduction of remote learning elements in the educational process. We have analyzed the works of researchers in this direction. They represent three key groups: methodological, empirical and reflexive.

The first group is methodological research. It is associated with the analysis and implementation of individual methods for new, mostly remote forms of work [2-5]. These works are usually based on the author's experience of testing methods, ways and technical means of remote work. These works represent a generalization of the positive and negative innovations aspects as a result of their implementation into the educational process. This group of studies is of great practical importance for educational organizations employees, as it allows us to assess the innovations potential

The second group is empirical research. It consists of works devoted to analyzing the applied innovations effectiveness and identifying problems in this direction based on the analysis of the results of various experiments, surveys, and experiments conducted with participants of the new educational paradigm [6-7]. They allow us to understand the real moods and capabilities of those individuals who find themselves in the conditions of the coronavirus spread. They had to face with the fact of imminent changes. The analyzed data can serve as an priceless material for work aimed at systematizing further educational policy, taking into account the discovered problems.

The third group is reflexive research. It includes the work of researchers who try to consider the issue of optimizing the educational process comprehensively, taking into account its updating, analyzing existing problems, and suggesting possible ways to solve these problems [8-15]. 
These are comprehensive works that provide possible material for updating educational relations, taking into account the problems that have already arisen in practice, including legal, economic and executive solutions.

Content risk analysis is seen in a small percentage of research. They are of a limited subject nature. For example, they are devoted to the organizations individual structures activities. For example, the experience of the Yekaterinburg Youth Centre is studied [16]. The research can also be devoted to the organizations individual structures forms of work. For example, the features of pedagogical practice in the form of an online camp are analyzed [17].

The peculiarity of these works is the consideration of educational process as a very broad process, without excluding educational activities. The researchers see the risks associated with the switch to remote learning. These risks lead to the educational process formalization. The scientists emphasize the importance of personal and emotional contact between a lecturer, a teacher or a professor and a student [18].

Based on the identified problem points in the content of the educational process during the pandemic, the need to involve auxiliary methods was identified. These means are carrying surveys and interviews. Our empirical studies were conducted as reactive mini-surveys in oral and written form in relation to the results of research conducted by other scientists. It was done in order to confirm or deny these results with the help of our respondents group. This group consisted from University students that were studying in the field of law. We have found it important to establish two key points. The first one is the question "How are the students ready for an innovative learning format?". The second question is "How do they organize their educational activities?". Our surveys have confirmed the our colleagues' conclusions on the point that students are least likely to choose an innovative style of responding to changes [19]. We can note that the need to study remotely with the help of technical means caused negative emotions in the majority of respondents. It was associated not only with the point that some people were unable to use new resources, but also with an unwillingness to learn how to use them. The independent choice of content for studying leads students to turn to educational videos on YouTube [12]. The researchers that asked the same question have made the similar conclusion. We have also found that students rarely put the quality of educational content in the foreground. They are more interested in the time they spend on understanding the topic.

Thus, the combination of theoretical and practical methods allowed us to draw a number of conclusions about the pedagogical risks that are present in educational activities as a consequence of the coronavirus spread, and the transformation of educational relations in this regard. Using the forecasting method, we formulated the main groups of content risks in the contingent-risk field.

\section{RESEARCH RESULTS}

As a result of the study, we have found that, despite dramatic changes in educational relationships, most of the participants in these relationships were able to adapt to the new format of work without significant loss of quality. We can also say that there is a certain qualitative growth. Students' grades in the process of intermediate and final assessment this year have become higher. Formal indicators of the educational process, with a number of exceptions, have been adjusted. The time of classes, forms of work and thematic content of courses did not change. However, the content components in the personality formation aspect as a result of comprehensive training could not be fully preserved, which had an impact on students and will have its social consequences in the future. The most affected are those competencies that can be formed exclusively in the team with personal communication of its participants. For example, universal competencies that are contained in the Federal Educational Standards, especially the УК-3,4,5,6.

We have identified 3 groups of risks that can have a serious impact on the formation of society in the future. We think that this impact will be seen when the generation, affected by the pandemic, becomes independent in professional and social terms. The most serious risks are social, professional, and personal, according to our research.

\section{DISCUSSION OF FINDINGS}

The educational space has changed dramatically, but its content is still aimed at personal development. Taking into account modern changes, this aspect is moving to the foreground. The educational paradigm has undergone some significant transformations. These transformations are meaningful not only for the entire system, but also for individual participants of educational relations.

Despite the fact that the problems of lecturers and professors to switch to a new type of work are more often discussed, students also find themselves in an uncomfortable situation and continue experiencing stress. We agree with the opinion that during a pandemic, "the regular sequence of actions, the clear hierarchy of values of a place, a thing, or home changes... social stereotypes change". And these changes are directly proportional to the age of the participants in the relationship. The older a person is, the longer it takes to adapt to innovations [20]. The situation in this case is quite complex, because students have already had their own idea of the standard educational process, of the roles of a "professor" and a "student" in it, of the tasks that they face, and, most importantly, of the work form. Any changes were as dramatic for them as they were for the lecturers and professors. And for many students, the new conditions were less clear, because they violated the usual boundaries of communication zones. The technical means that were used in personal space suddenly became a means of 
obtaining academic knowledge. The problem aggravates by the fact that traditionally schools, colleges and universities did not encourage the use of gadgets for educational purposes.

This leads to students' disorientation, communication norms violation, failure in the style of communication, which in the new conditions with a high workload of lecturers escapes their field of view. Some students, who were excellent speakers in the audience, completely distance themselves from communication, because they cannot demonstrate their skills in this working mode. Others refuse to communicate at all, because they assume that there is no existing need to establish contact. So, we can say that one of the key УК-4 (communication) competencies is not formed completely.

The first risk in this regard seems to us, first of all, professional within the framework of the communication field, when specialists are not ready to communicate in a professional environment at the proper level. We will appeal to УК-3 (teamwork and leadership). The formation of these skills is associated with working in a group, but if we take into account the specifics of indirect communication, it becomes almost impossible. The main pedagogical traditional work forms like working in small groups, debating, aquarium discussions lose their meaning in the context of remote communication. These methods can be used, but the educational effect becomes less significant. Secondly, this is a personal risk. Many people will not be able to fully express their thoughts after completing their education course. So they will face problems, like misunderstanding in both professional sphere and day-to-day life. And this will lead to provoking conflicts.

It should be noted that if students are in the same classroom, they are forced to establish contact with their groupmates and lecturers, thereby developing their social skills. If we consider the remote communication, everyone is alone. Socialization has not only slowed down, but practically stopped, because it was imposed on state measures for self-isolation for citizens. Many students note that they no longer communicate with their groupmates, and the existing groups in social networks are empty. Pay attention to the fact that most families are still created by people who met during their student years. So there is a risk that a whole generation of families whose conscious age fell on the pandemic will not be created.

Therefore, we can also define this problem as a social risk. The lack of socialization and loss of social connections between students may become a sufficient problem. This risk can have various consequences from purely personal problems (people will not make a family or friends) to social ones (dissatisfaction with the state, participation in public riots).

As it turned out during the remote learning, most of the students could not organize themselves while completing homework, because earlier the organizing function was taken over by lecturers in the audience. They kept the track of time, reminded about the deadlines, controlled the process. The abrupt switch to remote learning revealed another problem. The outflow of those students who did not have the proper competence according to УK-6 (selforganization and self-development). They could not apply the principles of time management and claimed that the load has become too large. Students are not ready for independent control, they can not adapt to new reality, which leads to problems with sleep, exceeding the reasonable limit of work at the computer, irrational waste of time due to lack of focus on one thing.

For many students, the educational strategy is unbalanced. If earlier academic and extracurricular work complemented each other, then while the remote learning, the learning process began to occupy almost all the time. And this, to some extent, led to the increase in scores. In particular, the results of the Unified State Exam in 2020 in subjects such as Russian language, literature, social studies, history have increased, and the percentage of excellent students in many groups has sharply increased. However, according to the results of monitoring the students-teachers formation quality, the scientists have proven that the high score at the Unified State Exam is not always a condition for the formation of a high-qualified specialist in the future [21]. Thus, it is impossible to talk about full-fledged all-round development of the individual in the conditions of individual unilateral development when obtaining theoretical knowledge at the expense of reducing practical skills.

This risk is complex. Failure to self-organize, to manage time and life will lead to inefficient work and psychological problems.

Thus, there are a lot of risks that can negatively affect the generation that has become participants in such period. The educational process is a multidimensional concept that represents "the broadcast of cultural, spiritual and moral experience and professional skills" [22]. TIn particular, it is provided that in higher education institutions there is a unique academic environment that has been developing for decades. It has traditionally been a part of live communication with leading professors. Therefore, passing the socio-cultural development stages of a person in the learning process is associated with the concept of "personal culture". It is understood as an integral product of the educational process [23], the formation of which becomes difficult when the process itself breaks down into separate elements with the loss of a valuable component, the contact work of the professor and the student.

It should be noted that risks have possible negative consequences. At the same time, it is already possible to observe some positive aspects of the ongoing changes. During the pandemic, some professors and students began to work more smoothly, i.e. they were able to implement a subject-subject model of interaction. New models of interactive technologies for self-regulation formation were developed [24]. Students' interest in additional literature was noted, and many people used the opportunities for more active interaction with professors, taking into account remote communication. We can assume that the above risks are minimized for these categories of professors and students. But the stressful nature of innovations still matters. 


\section{CONCLUSIONS}

As a result of the study, we have found that the coronavirus spread consequences will be observed in various areas of human life for a significant period of time. The changes will be mostly noticed in those areas where the key element of the system's functioning is human capital.

The modern educational system has undergone significant transformations in such a short period of time. And it has certainly affected those people, who found themselves part of it during this unstable period. A number of changes can be noticed right now, but they are mostly formal in nature, calculated at the moment. Meaningful changes have a delayed effect and their impact on students' personalities may only appear in a few years or under certain social conditions.

There are several groups of risks that can lead to negative consequences both in the individuals' lives and in the society development. The first group is associated with the lack of socialization or its limitation. This can lead to social instability, the growth of conflicts on the scale of both certain communities and the whole society. Professional risks are associated with the fact that most students are not able to work remotely in a group and establish productive communication with colleagues. This can lead to professional conflicts and to the inability of some specialists to fully perform official tasks due to the discrete nature of training. Personal risks relate to certain groups of students who have not been able to make friends, have been isolated. This will affect their individual behavior over time.

Thus, these risks can have serious consequences, but they can be prevented if the specifics of the pandemic impact on a person are comprehensively assessed, taking into account the scope of their activities during the changing situation in the world. Problems in the educational environment can be leveled by updating lost competencies in the process of further education and creating an educational model that takes into account the gaps that have arisen at the current moment. Thus, the existing risks can be transformed into a constructive basis for future positive innovations.

\section{REFERENCES}

[1] Romanovsky G.B. 2019-NCOV as a hybrid threat to the human rights system // Constitutional and municipal law. 2020. No. 7. P. 34-38.

[2] Abramyan G.V., Katasonova G.R. Remote education organization features in higher education institutions in the conditions of self-isolation of citizens during a viral pandemic // Modern problems of science and education. 2020. No. 3.

[3] Vinnikova I.S., Kuznetsova E.A. Features of using remote learning methods in modern conditions of self- isolation // Problems of modern pedagogical education. 2020. No. 67-1. P. 53-56.

[4] Gromova T.V. Determining the University teachers readiness level for distance learning // Problems of education quality management. 2020. P. 113-116. DOI 10.37539/KO186.2020.84.46.004

[5] Makarov A.D., Makarova O.A. Methods of conducting the exam in the format of communication programs MICROSOFT TEAMS, ZOOM //

Clusterization of the digital economy: global challenges. 2020. P. 395-403. DOI:

10.18720/IEP/2020.5/49

[6] Blinov V. I., Sergeev I. S., Esenina E. Y. Abrupt distance learning: the first month of the emergency (based on the results of Express research and Express survey): 2 hours // Professional education and the labor market. 2020. No. 2. P. 6-33. DOI 10.24411/23074264-2020-10201

[7] P Petruneva R.M., Avdeyuk O.A., Petruneva.Y.V., Avdeyuk D.N. problems of remote education from the point of view of the professors: coronavirus lessons// systems Primo aspectu. 2020. No. 2 (42). P. 65-71.

[8] Zhiltsov N.A., Cherdakov O.I. Trends in virtual education (lessons from COVID-19) // Legal world. 2020. No. 7. P. $18-22$

[9] Iseev R.R. Remote monitoring of academic performance and students' certification in a pandemic experience //The Newman in Foreign Policy. 2020. Vol. 3. No. 54 (98). P. 6-20.

[10] Kirillova T.V. Professor's professionalism and selfdevelopment as a condition for improving the quality of professional training in departmental educational organizations // Pedagogical questions. 2020. No. 4-2. P. 177-180.

[11] Orusova O.V. How the coronavirus changed the higher education system: universities switch to remote learning analysis // Scientific review. Series 1: Economics and law. 2020. No. 3. P. 184-195.

[12] Pashkin S.B., Lisovskaya N.B., Pchelkin V.O., Sarkisova E.A. Digitalization as a new direction in education // Educational Bulletin. Awareness. 2020. Vol. 22. No. 6. P. 21-30. http://dx.doi.org/10.26787/nydha-2686-6846-2020-226-21-30 
[13] Shabanov G.A. Five lessons from the pandemic // Higher education today. 2020. No. 7. P. 11-17. DOI: 10.25586/RNU.HET.20.07.P.11

[14] Shabanov G.A., Rastyagaev D.V. University digitalization: reality and expectations // Higher education today. 2020. No. 1. P. 2-7. DOI: 10.25586/RNU.HET.20.01.P.02

[15] Shmurygina O.V. Educational process in the context of a pandemic // Professional education and labor market. 2020. No 2. P. 51-52. DOI $10.24411 / 2307-4264-2020-10210$

[16] Yakovlev M.E., Vaulina K.O., Popova N.V. Coronavirus as a challenge to social pedagogy in Russia // Social pedagogy in Russia. Scientific and methodological journal. 2020. No. 3. P. 23-26.

[17] Shcherbakova E.V., Shcherbakova T.N. Experience of pedagogical communication with students in the organization of remote summer practice // Modern pedagogical education. 2020. No. 7. P. 4-8.

[18] Martianov E.Y., Martianova E.G. Experience of system analysis of remote learning in Russian schools during the coronavirus pandemic. Philosophical and methodological discourse // In the collection: The concept of "knowledge society" as a new form of postindustrial society. International scientific and practical conference collection of articles. Ufa, 2020. P. 241-247.

[19] Buravleva N.A., Bogomaz S.A. Personal characteristics of students as predictive characteristics of their readiness for innovation // Siberian psychological journal. 2020. No. 76. P. 155-180. DOI: $10.17223 / 17267080 / 76 / 10$

[20] Murzin A.D. Economics of education and culture during the pandemic // Economics vector. 2020. No. 4 (46).

[21] Nagovitsyn R.S., Osipov A.Yu., Kudryavtsev M.D., Bliznevskaya V.S. A High Score for the Unified State Examination for an Applicant - A "Quality" Graduate for the Educational System in the Future? // European Journal of Contemporary Education. 2020. T. 9. № 1. C. 89-101. DOI: 10.13187/ejced.2020.1.89

[22] Alekseeva M.I. Specifics of professor-student relations in a modern pedagogical university // E-Scio. 2020. No. 8 (47). P. 255-260.

[23] Khudyakova N.L., Nevelev A.B., Neveleva V. S. Personal culture as the goal of continuous developing education: philosophical and methodological justification // Education and science. 2020. Vol. 22. No. 7. P. 9-32. DOI: 10.17853/1994-5639-2020-7-9-32

[24] Odinokaya M., Krepkaia T., Sheredekina O., Bernavskaya M. The culture of professional self realization as a fundamental factor of students' internet communication in the modern educational environment of higher education. Education Sciences. 2019. V. 9. No 3. P. 187 DOI: 10.3390/educsci9030187 